\title{
Agôn
}

Revue des arts de la scène

Critiques | Saison 2012-2013

\section{Le Retour d'Ulysse dans sa patrie}

Monteverdi vu par Christophe Rauck

\section{Caroline Mounier-Vehier}

\section{(2) OpenEdition \\ Journals}

Édition électronique

URL : http://journals.openedition.org/agon/2670

DOI : 10.4000/agon.2670

ISSN : 1961-8581

Éditeur

Association Agôn

Référence électronique

Caroline Mounier-Vehier, "Le Retour d'Ulysse dans sa patrie ", Agôn [En ligne], Critiques, mis en ligne le 04 juillet 2013, consulté le 23 septembre 2020. URL : http://journals.openedition.org/agon/2670 ;

DOI : https://doi.org/10.4000/agon.2670

Ce document a été généré automatiquement le 23 septembre 2020

Association Agôn et les auteurs des articles 


\title{
Le Retour d'Ulysse dans sa patrie
}

\author{
Monteverdi vu par Christophe Rauck
}

\section{Caroline Mounier-Vehier}

\section{RÉFÉRENCE}

Le Retour d'Ulysse dans sa patrie, opéra composé par Claudio Monteverdi sur un livret de Giacomo Badoaro (1640), direction musicale de Jérôme Correas, mise en scène de Chritophe Rauck - Spectacle créé le 11 janvier 2013 au Théâtre Firin Gémier, La Piscine de Châtenay-Malabry - du 21 mars au 6 avril 2013 au TGP-CDN de Saint-Denis, tournée en France de février à juin 2013.

1 Trois ans après un très beau Couronnement de Poppée, le TGP de Saint-Denis accueille un autre opéra de Monteverdi, Le Retour d'Ulysse dans sa patrie. Le compositeur n'est pas le seul point commun de ces deux spectacles, qui partagent aussi le même tandem formé du metteur en scène Christophe Rauck et du chef d'orchestre Jérôme Correas, le même ensemble musical, les Paladins, et certains chanteurs. 


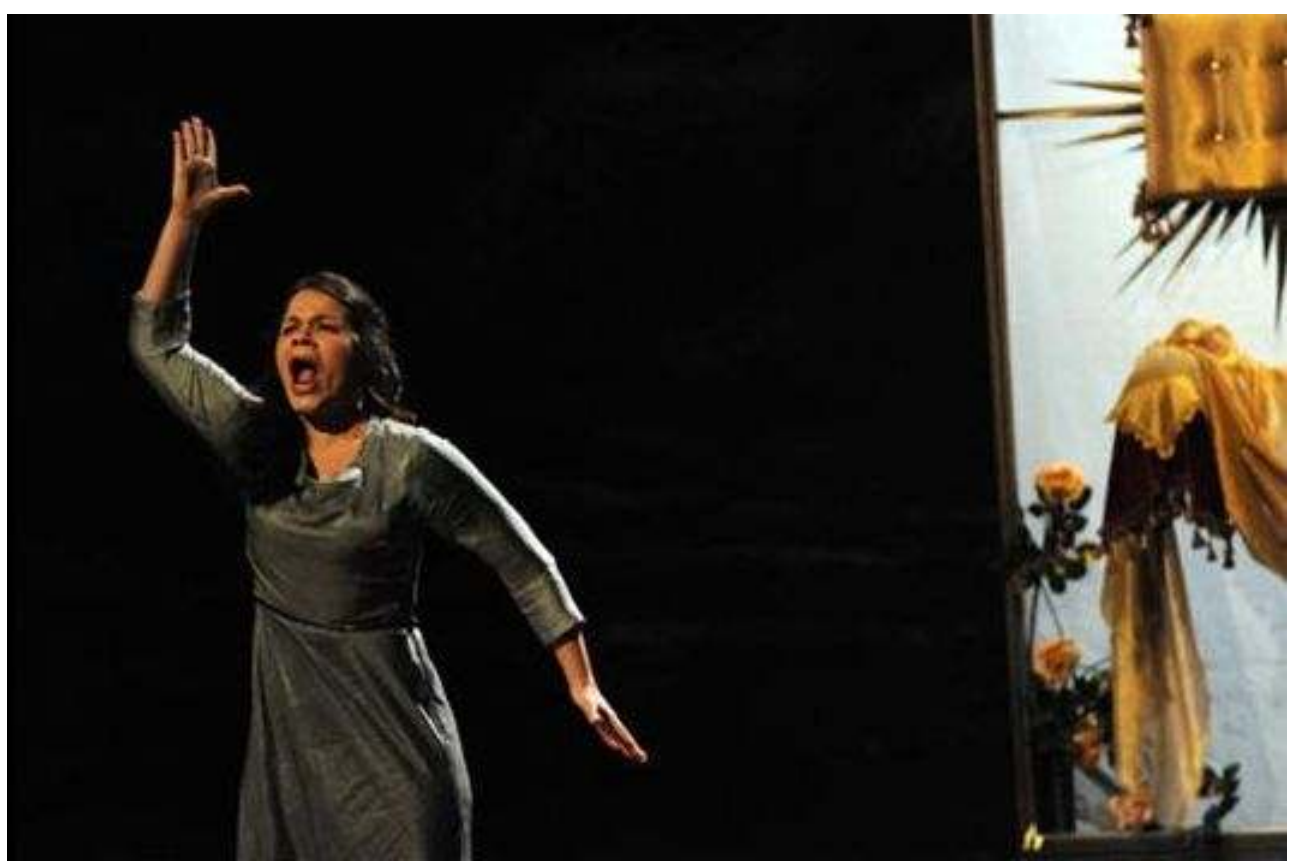

Le Retour d'Ulysse dans sa patrie, opéra composé par Claudio Monteverdi, mise en scène de Christophe Rauck - du 21 mars au 6 avril 2013 au TGP-CDN de Saint-Denis, tournée en France de février à juin 2013.

(c) Anne Nordmann

2 C'est avec beaucoup de poésie qu'est représenté le retour d'Ulysse à Ithaque, son royaume et sa patrie. Le livret de Badoaro s'inspire des chants XIII à XXIV de L'Odyssée : après un long périple, Ulysse rejoint sa terre, où l'attendent un fils qui ne le connaît pas, Télémaque, ainsi que quelques épreuves qu'il lui faut surmonter avant de pouvoir retrouver son trône et son épouse, la fidèle et patiente Pénélope. Les personnages incarnés par les chanteurs prennent place dans la même boîte scénique que celle du Couronnement, avec évidemment quelques changements de décor. Christophe Rauck et son équipe (scénographe, costumière...) montrent une fois de plus toute la finesse dont ils sont capables en proposant des images scéniques aussi justes qu'harmonieuses. Dans une grande salle du palais, des femmes-bougies, moulées sur le modèle de Pénélope, se consument, mélancolique évocation du temps qui passe et de la vie qui fuit dans une attente indéfinie. Une lune apparaît par moments lors des retrouvailles d'Ulysse et de Télémaque, image d'une étrange poésie de la rencontre. Lune maîtresse des marées, elles-mêmes incessants mouvements de la mer sur laquelle Ulysse a vogué tant de mois avant de retrouver son pays et son trône. Lune qui éclaire ou cache, dans un mouvement de descente et de montée, à l'image de l'espoir et du doute qui assaillent le cœur de Télémaque à la vue d'un père qu'il n'a jamais connu. Quelques images plus drôles aussi, comme le personnage de ce glouton qui parcourt la scène de manière un peu grotesque ou la compétition des prétendants de Pénélope, qui s'efforcent vainement de tendre le fameux arc d'Ulysse avant de se voir débouter par un vieillard qui n'est autre que le maître des lieux. La reconnaissance finale est étrange : Pénélope et Ulysse se retrouvent avec une joie mêlée de malaise, comme s'il ne leur était plus possible de se reconnaître tout à fait après vingt ans d'absence. 
3 Si ce Retour d'Ulysse est remarquable à bien des égards, le travail théâtral et musical mené avec les chanteurs est sans doute l'un des aspects les plus surprenants et réjouissants du spectacle. Ces chanteurs jouent. On ne s'étonne plus aujourd'hui que des chanteurs jouent à l'opéra, mais ceux-là troublent les frontières et s'assument comme artistes à part entière, aidés en cela par une pratique du chant somme toute peu courante. En effet, la direction du chant de Jérôme Correas sollicite chez les chanteurs une maîtrise de leur voix qui leur permette le discours parlé comme le discours chanté et toutes les nuances qui peuvent exister entre ces deux extrêmes. Un exemple frappant de la réussite de cette méthode se trouve chez Blandine Folio Peres, la mezzosoprano qui interprète le rôle de Pénélope. Sa voix glisse harmonieusement et cabriole entre parlé et chanté, selon ce que nécessite chaque situation d'un point de vue musical et dramaturgique. Ces jeux de voix sont indissociables d'un jeu de théâtre maîtrisé. On est loin ici d'une dichotomie souvent trop franche encore entre jeu et chant. On est loin aussi d'un jeu outrancier, forcé, un peu caricatural mais acceptable, parce qu'après tout, les chanteurs ne sont pas supposés être des acteurs. Eh bien, si : à Saint-Denis, les chanteurs nous ont montré qu'ils pouvaient aussi jouer et qu'ils pouvaient même s'appuyer sur le chant pour cela, soutenus par les musiciens des Paladins, complices et attentifs.

4 La force de ce spectacle réside sans doute dans le bel équilibre instauré par l'ensemble des artistes entre l'interprétation scénique et la musique : portés par la musique, les chanteurs s'insèrent dans de poétiques images où leurs personnages prennent vie. $\mathrm{Ce}$ spectacle nous rappelle, s'il en était besoin, qu'à l'opéra, on est indéniablement aussi au théâtre. 